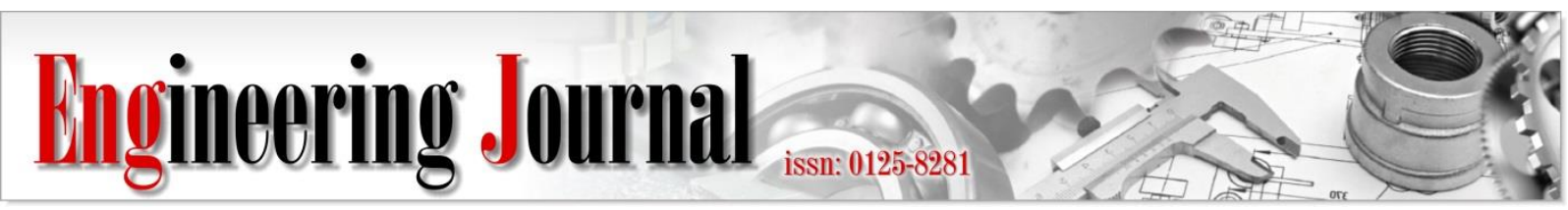

Article

\title{
PDMS Material Models for Anti-fouling Surfaces Using Finite Element Method
}

\author{
Kotchakorn Thanakhun ${ }^{\mathrm{a}}$ and Tumrong Puttapitukporn ${ }^{\mathrm{b}, *}$ \\ Department of Mechanical Engineering, Faculty of Engineering, Kasetsart University, Bangkok 10900, \\ Thailand \\ E-mail: akotch.work@gmail.com, bfengtop@ku.ac.th (Corresponding author)
}

\begin{abstract}
Ecofriendly anti-fouling surfaces are usually produced by lithographic techniques which will fabricate micropillar-like surfaces made of low surface energy materials such as Polydimethylsiloxane (PDMS). The purposes of this research were to investigate the most suitable Polydimethylsiloxane (PDMS) material model available in ANSYS APDL program to simulate structural behaviors of micropillars subjected to shear loading and to develop micropillar with improved lateral strength. In this research, PDMS material models were derived from experimental data from uniaxial tensile test. The accuracies of the PDMS material models, which were the Neo-Hookean, Mooney-Rivlin 3 and 5 parameters, Ogden (1, 2, 3 terms), Yeoh $\left(1^{\text {st }}, 2^{\text {nd }}, 3^{\text {rd }}\right.$ order $)$ and Arruda-Boyce material models, were evaluated and compared to experimental data from uniaxial tensile test and punch-shear test. Moreover, micropillars made of a pure PDMS and a Polyurethane Acrylate (PUA) core coated with PDMS were studied to compare their lateral strength under shear loading. We found that the most accurate material model to simulate both the uniaxial tension and shear loading was the Yeoh 3rd order material model; however, these accuracies would valid for small strain range. The lateral strength of a micropillar made of PUA core coated with PDMS was 8.67time of the one made of pure PDMS. The optimal coating thickness was $100 \mathrm{~nm}$ because of its lateral strength and manufacturing cost.
\end{abstract}

Keywords: Hyperelastic material models, finite element analysis, ANSYS, PDMS, micropillar.

ENGINEERING JOURNAL Volume 23 Issue 6

Received 22 July 2019

Accepted 25 October 2019

Published 30 November 2019

Online at http://www.engj.org/

DOI:10.4186/ej.2019.23.6.381 


\section{Introduction}

Anti-fouling surfaces are micropillar-like surfaces made of low surface energy materials by the lithographic techniques. As results, their surface roughness increased which will improve hydrophobic properties. These properties are regulated by the water wetting angle of the surface. Gomes, Souza and Silva [1] classified the wettability property of surfaces by a wetting angle. Firstly, if the wetting angle is under 90 degrees, it is called a hydrophilic surface. Secondly, if the wetting angle is between 90 to 150 degrees, it is called a hydrophobic surface. Thirdly, if the wetting angle is over 150 degrees, it is called a super-hydrophobic surface. Moreover, the anti-fouling surfaces are usually made of PDMS materials because of their low surface energy, unusual rheological properties, colorless, non-toxic, non-flammable, easy to fabricate, furthermore, the stiffness and surface adhesion properties can be controlled by a ratio of the PDMS monomers to curing agent [2]. Anti-fouling surfaces help to eliminate the attachment of microorganisms due to their low surface energy. Bixler and Bhushan [3] studied the effects of biofouling on human kinds. For instance, bacteria or viruses attached to medical equipment and other unavoidable places such as ladders, walls which may lead infection. Moreover, the attachment of microorganism effects on economics in terms of higher fuel cost and the lack of effectiveness of the heat exchanger due to barnacles. Since the mechanical properties of PDMS material depends on PDMS monomers to curing agent ratio, Wang, Volinsky and Gallant [4] were studied the effect of the PDMS monomers to curing agent on stiffness of PDMS material. The result declares that the higher ratio of PDMS monomers to curing agent leads to decrease of stiffness value. Mata, Fleischman and Roy [5] studied the effect of PDMS monomers to curing agent on thickness of PDMS coating on other materials. The authors found that the coating thickness decreased as PDMS monomers to curing agent ratio increased. The manufacturer recommended that the ratio of the PDMS monomers to curing agent should be 10:1 by weight. However, PDMS material doesn't have that high value of stiffness. Once the micropillars collapsed and contacted to their neighbors, the micropillars will never separate again due to Van der Waals forces [6]. As results, hydrophobic properties would blunder away. Rahmawan et al. [7] fabricated the PUA cylinder-shaped micropillars with nanoparticles of silica on top of micropillar's head and compared their shear adhesion strength to one of non-nanoparticles. The authors found that the micropillars with those silica particles returned much higher shear adhesion strength. The study of mechanical responses of hyperelastic materials (elastomers or rubberlike materials) subjected to external loads is frequently used the finite element method. Neo-Hookean material model is the simplest hyperelastic material model which is developed from Hooke's law. Xie et al. [8] analyzed the mechanical behaviors of an intervertebral disc (IVD) in which the elastic material model was compared to the Neo-Hookean material model in ABAQUS program. The FE results of the NeoHookean material model had much better capabilities to describe the mechanical behaviors. Tobajas, Ibarz and Gracia [9] studied the most suitable material model derived from experimental data of uniaxial tensile test for characterizing Santoprene 101-73 material manufactured by ExxonMobil. The constitutive material models were Neo-Hookean, Mooney-Rivlin, Ogden, Gent-Thomas, Arruda-Boyce and Yeoh which were evaluated by the Pseudo $\mathrm{R}^{2}$ method. The authors found that the Mooney-Rivlin material model showed the highest correlation on both strain energy density and stress-strain relationships. Smardzewski, Grbac and Prekrat [10] used the Mooney-Rivlin material model to describe behaviors of Polyurethane foam mattress using ABAQUS program. The FE results showed a good agreement to experimental data from compressive test. Nomoto et al. [11] studied the 2-dimentional rubber matrix by using the Mooney-Rivlin model which was curved fitting with experimental data from biaxial tensile test. The FE models consisted of a rubber matrix subjected to compressive loading and FE results of stress-strain relationship was valid only in the low strain region. Huri and Mankovits [12] studied the most suitable material model for rubberlike materials in ANSYS program. The Mooney-Rivlin and Yeoh material models were used to curve fitting experimental data from compressive test and the FE results were compared and evaluated using sum square of errors method. The authors found that the Yeoh material model was the most suitable model; however, FE results were valid only about $50 \%$ strain. Since the impossible frictionless compression testing could lead the abnormal behaviors at the later region of strain. Phromjan and Suvanjumrat [13] studied solid tires subjected to a compressive load. The material properties of the rubber were obtained from curve fitting experimental data from uniaxial compression test with several constitutive models which were Polynomial, Mooney-Rivlin, Yeoh, Arruda-Boyce and Ogden material models in MSC Marc program. The results showed that Ogden material model was the most accurate model with Pseudo $\mathrm{R}^{2}$ of $0.988-0.990$. Munroe and Sherwood [14] used the Ogden material model to curve fitting experimental data from compressive test of a baseball using the LS-DYNA V.971 program to analyze the hyperviscoelastic nature of each layer. The 
FE results of loads and displacements relationship correlated well with the experimental data. Gajewski, Szczerba and Jemiolo [15] modelled the elastomeric bridge bearing with the steel reinforcement subjected to compressive and shear loadings in ABAQUS program. The Neo-Hookean and Yeoh material models were used to curve fitting both uniaxial tension and simple shear test data to evaluate the most suitable material model. The authors found that the Yeoh material model showed the best prediction on the mechanical behaviors of the elastomeric bridge bearing. PDMS material is generally characterized as the hyperelastic material since PDMS material has nonlinear elastic response and Poison's ratio being nearly 0.5. Rathod et al. [16] used the finite element method to compare predictions of calculated tractions for PDMS micropillar geometries with different aspect ratios using linear and nonlinear constitutive models in ABAQUS program. The Neo-Hookean and Arruda-Boyce material model were studied and the author showed that the Neo-Hookean material model obtained the most accurate results. Carlescu, Prisacaru, and Olaru [17] studied silicone elastomer films made of PDMS material subjected to uniaxial tension. The PDMS material model was curved fitting to the experimental data from uniaxial tensile test using the NeoHookean, Mooney-Rivlin, Yeoh, Ogden, Arruda-Boyce and Van de Waals Models in the ABAQUS program. Their results showed that Mooney-Rivlin, Ogden 2 terms and Yeoh $3^{\text {rd }}$ order were obtained as the most accurate results. Kim, Kim and Jeong [18] studied the most appropriate FE model for a PDMS material in MSC Marc program. Here, the PDMS material models were the Neo-Hookean, Mooney-Rivlin 3 parameters and Ogden 2 terms material model. The authors showed that Ogden 2 terms obtained the most accurate results. Nunes [19] proposed the new PDMS material model used to study mechanical behaviors of PDMS bonding between two steel A36 plates. The author showed that for shear loading, his PDMS material model was more accurate than ones of the Mooney-Rivlin material model.

The objectives of this research were to investigate accuracies of PDMS material models available in ANSYS APDL program for analyzing mechanical behaviors of micropillars subjected to shear loading and to develop micropillars with improved lateral strength. The PDMS material models were curved fitting to uniaxial tensile test data. After that, we evaluated the accuracies of the PDMS material models on tensile and shear loading with experimental data. Finally, mechanical behaviors of micropillar fabricated from a core made of a PUA material coated with a PDMS material, were studied and compared its lateral strength to one made of a pure PDMS material under the shear loading.

\section{Theory}

Hyperelastic material models are developed to describe a non-linear stress-strain relationship of hyperelastic materials either elastomers or rubbers. The constitutive material models are under an assumption of nonlinear stress-strain relationship in which the material is capable to reverse into the previous shape after unloaded. The flexibility does not rely on strain rate and the material is an isotropic and incompressible [20]. The typical strain energy density function $W$ can be written in terms of the stretch ratios $\lambda$ and invariants $\bar{I}$ as follows:

$$
W=\sum_{i+j=1}^{N} C_{i j}\left(\bar{I}_{1}-3\right)^{i}\left(\bar{I}_{2}-3\right)^{j}+\sum_{k=1}^{N} \frac{1}{d_{k}}(J-1)^{2 k}
$$

where $C_{i j}$ are material constants, $d_{k}$ are constants of material compressibility, $J$ is determinant of the elastic deformation gradient, $N$ is the number of terms in the equation and invariants $\bar{I}$ are

$$
\begin{gathered}
\bar{I}_{1}=\lambda_{1}^{2}+\lambda_{2}^{2}+\lambda_{3}^{2} \\
\bar{I}_{2}=\lambda_{1}^{2} \lambda_{2}^{2}+\lambda_{2}^{2} \lambda_{3}^{2}+\lambda_{3}^{2} \lambda_{1}^{2} \\
\bar{I}_{3}=\lambda_{1}^{2} \lambda_{2}^{2} \lambda_{3}^{2}
\end{gathered}
$$


The stretch ratio $\lambda$ in the $i$-direction can be written as

$$
\lambda_{i}=\frac{L_{i}}{\left(L_{O}\right)_{i}}=1+\varepsilon_{i}
$$

where $\left(L_{0}\right)_{i}, L_{i}$ and $\varepsilon_{i}$ are the initial length, the instantaneous length and the engineering strain in the $i$ direction respectively. The principal stress $\sigma$ in the $i$-direction is derived from the strain energy function as

$$
\sigma_{i}=\lambda_{i} \frac{\partial W}{\partial \lambda_{i}}
$$

\subsection{Hyperelastic Material Models}

A hyperelastic material model is a type of constitutive model for nonlinearly elastic materials for which the stress-strain relationship can derive from a strain energy function.

\subsubsection{Neo-Hookean material model}

The Neo-Hookean model is the simplest form of the strain energy function $W$ which is modified from Hooke's law. The Neo-Hookean material model can be written by Eq. (7) as

$$
W=\frac{\mu}{2}\left(\bar{I}_{1}-3\right)+\frac{1}{d}(J-1)^{2}
$$

where $W$ is strain energy per unit reference volume, $\bar{I}_{1}$ is the first deviatoric strain invariant, $\mu$ is an initial shear modulus of the material, $d$ is material incompressibility parameter and $J$ is determinant of the elastic deformation gradient, $F$.

\subsubsection{Mooney-Rivlin material model}

The Mooney-Rivlin material model has been developed from the Neo-Hookean material model in which the function of strain energy density depends on the first and second invariants. There are several forms of these material models which are 2, 3, 5 and 9 parameters being available in ANSYS program which can be expressed as Eq. (8-11).

The Mooney-Rivlin 2 parameters can be expressed as

$$
W=C_{10}\left(\bar{I}_{1}-3\right)+C_{01}\left(\bar{I}_{2}-3\right)+\frac{1}{d}(J-1)^{2}
$$

The Mooney-Rivlin 3 parameters can be expressed as

$$
W=C_{10}\left(\bar{I}_{1}-3\right)+C_{01}\left(\bar{I}_{2}-3\right)+C_{11}\left(\bar{I}_{1}-3\right)\left(\bar{I}_{2}-3\right)+\frac{1}{d}(J-1)^{2}
$$

The Mooney-Rivlin 5 parameters can be expressed as

$$
W=C_{10}\left(\bar{I}_{1}-3\right)+C_{01}\left(\bar{I}_{2}-3\right)+C_{20}\left(\bar{I}_{1}-3\right)^{2}+C_{11}\left(\bar{I}_{1}-3\right)\left(\bar{I}_{2}-3\right)+C_{02}\left(\bar{I}_{2}-3\right)^{2}+\frac{1}{d}(J-1)^{2}
$$


The Mooney-Rivlin 9 parameters can be expressed as

$$
\begin{aligned}
W= & C_{10}\left(\bar{I}_{1}-3\right)+C_{01}\left(\bar{I}_{2}-3\right)+C_{20}\left(\bar{I}_{1}-3\right)^{2}+C_{11}\left(\bar{I}_{1}-3\right)\left(\bar{I}_{2}-3\right)+C_{02}\left(\bar{I}_{2}-3\right)^{2}+C_{30}\left(\bar{I}_{1}-3\right)^{3} \\
& +C_{21}\left(\bar{I}_{1}-3\right)^{2}\left(\bar{I}_{2}-3\right)+C_{12}\left(\bar{I}_{1}-3\right)\left(\bar{I}_{2}-3\right)^{2}+C_{03}\left(\bar{I}_{2}-3\right)^{3}+\frac{1}{d}(J-1)^{2}
\end{aligned}
$$

where $W$ is strain energy per unit reference volume, $C_{10}, C_{01}, C_{20}, C_{11}, C_{02}, C_{30}, C_{21}, C_{12}$ and $C_{03}$ are material constants characterizing the deviatoric deformation of the material, $\bar{I}_{1}$ is the first deviatoric strain invariant, $\bar{I}_{2}$ is the first deviatoric strain invariant, $d$ is material incompressibility parameter and $J$ is determinant of the elastic deformation gradient, $F$.

\subsubsection{Ogden material model}

The strain energy density function of the Ogden model can be expressed by Eq. (12). There are 3 forms of the Ogden models being available in ANSYS program which are Ogden 1, 2 and 3 terms.

$$
W=\sum_{i=1}^{N} \frac{\mu_{i}}{\alpha_{i}}\left(\bar{\lambda}_{1}^{\alpha_{i}}+\bar{\lambda}_{2}^{\alpha_{i}}+\bar{\lambda}_{3}^{\alpha_{i}}-3\right)+\sum_{k=1}^{N} \frac{1}{d_{k}}(J-1)^{2 k}
$$

where $W$ is strain energy potential, $\bar{\lambda}_{p}(p=1,2,3)=$ deviatoric principal stretches, defined as $\bar{\lambda}_{p}=J^{-\frac{1}{3}} \lambda_{p}$ while $\lambda_{p}$ is principal stretches of the left Cauchy-Green tensor, $J$ is determinant of the elastic deformation gradient, $\mu_{i}, \alpha_{i}$ and $d_{k}$ are material constants and $N$ imply the number of terms in the equation which are usually below 3 .

\subsubsection{Yeoh material model}

The Yeoh material model expresses the strain energy density function depending on only first invariant as shown in following equation, Eq. (13). There are 3 forms of the Yeoh models which are Yeoh 1st, $2^{\text {nd }}$ and $3^{\text {rd }}$ order.

$$
W=\sum_{i=1}^{N} C_{i 0}\left(\bar{I}_{1}-3\right)^{i}+\sum_{i=1}^{N} \frac{1}{d_{k}}(J-1)^{2 k}
$$

where $W$ is strain energy potential, $\bar{I}_{1}$ is the first deviatoric strain invariant, $J$ is determinant of the elastic deformation gradient, $C_{i 0}$ and $d_{k}$ are material constants and $N$ imply the number of terms in the equation which are usually below 3 .

\subsubsection{Arruda-Boyce material model}

The Arruda-Boyce material model, known as 8-chain model, which was developed based on a molecular chain network (hexahedron) and only first invariant is expressed in the material model as shown in Eq. (14).

$$
\begin{aligned}
W & =\mu\left[\frac{1}{2}\left(\bar{I}_{1}-3\right)+\frac{1}{20 \lambda_{L}^{2}}\left(\bar{I}_{1}^{2}-9\right)+\frac{11}{1050 \lambda_{L}^{4}}\left(\bar{I}_{1}^{3}-27\right)\right. \\
& \left.+\frac{19}{7000 \lambda_{L}^{6}}\left(\bar{I}_{1}^{4}-81\right)+\frac{519}{673750 \lambda_{L}^{8}}\left(\bar{I}_{1}^{5}-243\right)\right]+\frac{1}{d}\left(\frac{J^{2}-1}{2}-\ln J\right)
\end{aligned}
$$


where $W$ is strain energy potential, $\bar{I}_{1}$ is the first deviatoric strain invariant, $\mu$ is an initial shear modulus of the material, $\lambda_{L}$ is the limiting network stretch, $d$ is material incompressibility parameter and $J$ is determinant of the elastic deformation gradient.

\subsection{Accuracy of Finite Element Material Models}

The comparison of constitutive material models in ANSYS program were evaluated by Pseudo R-squared method which can be calculated with Eq. (15).

$$
R_{E \text { fron }}^{2}=1-\frac{\sum_{i=1}^{N}\left(y_{i}-\hat{\pi}_{i}\right)^{2}}{\sum_{i=1}^{N}\left(y_{i}-\bar{y}\right)^{2}}
$$

Where, $y_{i}$ is the stress from the laboratory, $\hat{\pi}_{i}$ is the stress from finite element analysis, $\bar{y}$ is the mean of the stresses from the laboratory and $N$ is a total number of data.

\section{Methodology}

\subsection{Uniaxial Tension}

\subsubsection{Laboratory experiment of uniaxial tension test}

The uniaxial tensile tests were performed on the Servo-Hydraulic Universal Testing Machine (UTM Instron 5501R). The tests were conducted on 3 dumbbell-shaped specimens (based on ASTM D412 Die C) at room temperature of $25^{\circ} \mathrm{C}$. Specimens were made of a PDMS material having the PDMS monomers to a curing agent ratio of 10:1. Figure 1 illustrates the PDMS specimen size which had the gage width of $2.5 \mathrm{~mm}$, the total specimen length of $65 \mathrm{~mm}$, the gage length of $30 \mathrm{~mm}$ and the curvature radius of $25 \mathrm{~mm}$. The actual specimens were cut by a $\mathrm{CO}_{2}$ laser and their dimensions are shown in Table 1. The stress-strain relationships were obtained as shown in Fig. 2.

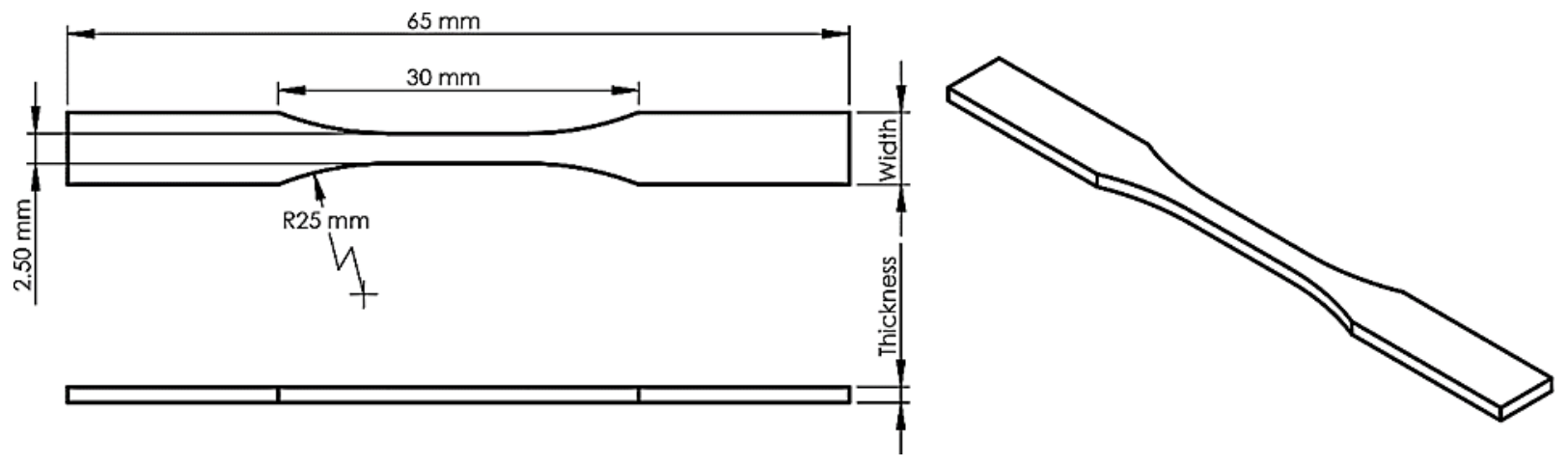

Fig. 1. Dimension of tensile specimens.

Table 1. The actual sizes of tensile specimens.

\begin{tabular}{ccc}
\hline Specimen number & Width $(\mathrm{mm})$ & Thickness $(\mathrm{mm})$ \\
\hline 1 & 6.028 & 1.426 \\
2 & 6.016 & 1.290 \\
3 & 5.979 & 1.222 \\
\hline
\end{tabular}




\subsubsection{Finite element analysis of a uniaxial tension test}

The finite element analyses were performed to determine accuracies of hyperelastic material models which were available in ANSYS Mechanical APDL program. The finite element model had only a gage length portion to prevent numerical difficulties which had $2.5-\mathrm{mm}$ wide, $30-\mathrm{mm}$ long and $1.313-\mathrm{mm}$ thick as shown in Fig. 3. The FEM were meshed using the SOLID186 element which was a higher order 3-D 20node solid element. This model was consisted of 64214 nodes with 13650 elements. The hyperelastic material models were used the Neo-Hookean, Mooney-Rivlin 3 and 5 parameters, Ogden (1, 2, 3 terms), Yeoh $\left(1^{\text {st }}, 2^{\text {nd }}, 3^{\text {rd }}\right.$ order$)$ and Arruda-Boyce material models where the material constants were illustrated in Table 2-6. The boundary conditions were that one end was fixed in all degree of freedom while the nodes attached to other end were constrained displacement in the z-direction and were gradually applied the displacement of $30 \mathrm{~mm}$.

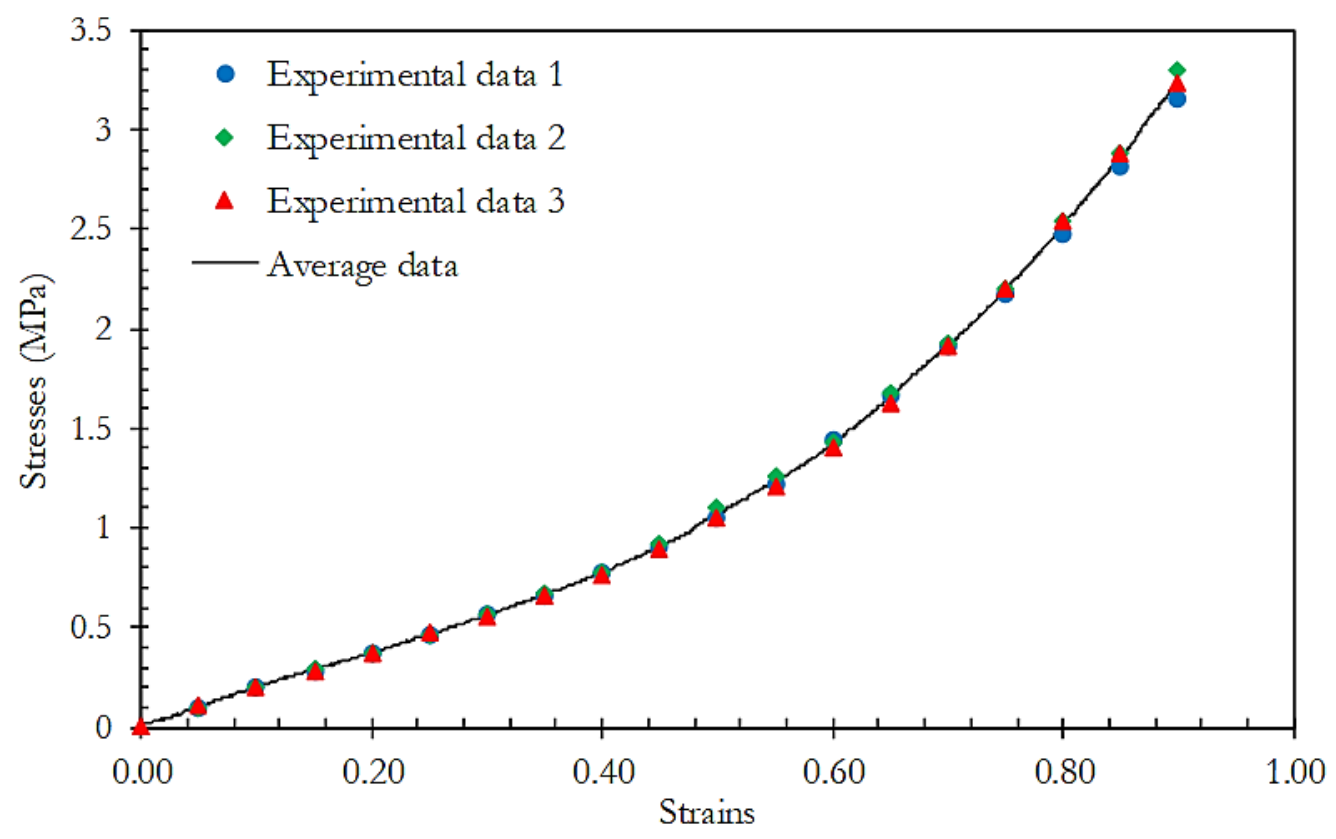

Fig. 2. Plot of stresses vs strains of experimental data and the average data from uniaxial tensile test.

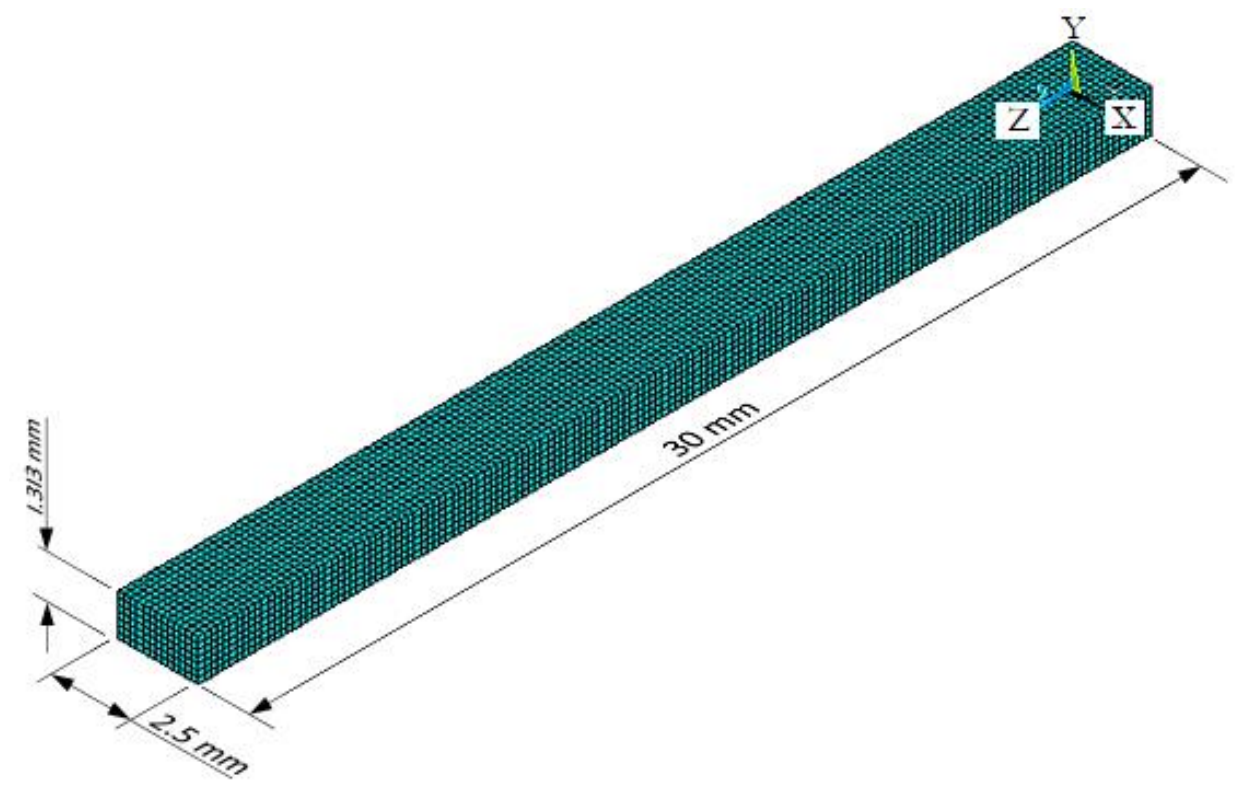

Fig. 3. FE model of a tensile test specimen. 
Table 2. The Neo-Hookean material model.

\begin{tabular}{ccc}
\hline Material model & $\mu$ & $d$ \\
\hline Neo-Hookean & 0.91156 & 0 \\
\hline
\end{tabular}

Table 3. The Mooney-Rivlin material model.

\begin{tabular}{|c|c|c|c|c|c|c|}
\hline Material model & $C_{10}$ & $C_{01}$ & $C_{11}$ & $C_{20}$ & $C_{02}$ & $d$ \\
\hline Mooney-Rivlin 3 parameters & -0.54115 & 0.97146 & 0.49612 & & & 0 \\
\hline Mooney-Rivlin 5 parameters & -0.46701 & 0.88163 & -3.91278 & 1.54142 & 3.11667 & 0 \\
\hline
\end{tabular}

Table 4. The Ogden material model.

\begin{tabular}{cccccccccc}
\hline $\begin{array}{c}\text { Material } \\
\text { model }\end{array}$ & $\mu_{1}$ & $\alpha_{1}$ & $\mu_{2}$ & $\alpha_{2}$ & $\mu_{3}$ & $\alpha_{3}$ & $d_{1}$ & $d_{2}$ & $d_{3}$ \\
\hline $\begin{array}{c}\text { Ogden 1 } \\
\text { term }\end{array}$ & 0.26299 & 4.75275 & & & & & 0 & \\
$\begin{array}{c}\text { Ogden 2 } \\
\text { terms }\end{array}$ & 0.04102 & 7.57032 & 422.57243 & 0.00276 & & & 0 & 0 \\
$\begin{array}{c}\text { Ogden 3 } \\
\text { terms }\end{array}$ & -149.35934 & 0.30898 & 0.26001 & 5.29229 & 494.13556 & 0.09382 & 0 & 0 & 0 \\
\hline
\end{tabular}

Table 5. The Yeoh material model.

\begin{tabular}{ccccccc}
\hline Material model & $C_{10}$ & $C_{20}$ & $C_{30}$ & $d_{1}$ & $d_{2}$ & $d_{3}$ \\
\hline Yeoh 1 1st $^{\text {order }}$ & 0.45578 & & & 0 & & \\
Yeoh 2 $^{\text {nd }}$ order & 0.33845 & 0.16787 & & 0 & 0 & \\
Yeoh 3 3rd order $^{\text {Yrd }}$ & 0.36428 & 0.07036 & 0.05307 & 0 & 0 & 0 \\
\hline
\end{tabular}

Table 6. The Arruda-Boyce material model.

\begin{tabular}{cccc}
\hline Material model & $\mu$ & $\lambda_{L}$ & $d$ \\
\hline Arruda-Boyce & 0.19003 & 0.97357 & 0 \\
\hline
\end{tabular}

\subsection{Punch-Shear Test}

\subsubsection{Laboratory experiment of the punch-shear test}

Experiments were performed using a Servo-Hydraulic Universal Testing Machine (UTM Instron 5501R). The punch-shear tests were conducted on 4 disc-shaped specimens (based on ASTM D732) at room temperature of $25^{\circ} \mathrm{C}$. Specimens were made of the PDMS material having the PDMS monomers to a curing agent ratio of 10:1 and had an outer diameter of $50 \mathrm{~mm}$ and an inner diameter of $11 \mathrm{~mm}$ as shown in Fig. 4a. The punch has an outer diameter of $25.37 \mathrm{~mm}$ and an inner diameter of $9.52 \mathrm{~mm}$ as shown in Fig. 4b. The actual specimens were cut by a $\mathrm{CO}_{2}$ laser and their thicknesses were shown in Table 7 . The graph of compressive forces (punch forces) versus vertical (axial) displacements of the tested specimens was obtained as shown in Fig. 5. The graphs of the vertical displacements and the compressive forces from the experiments were scattered, because of uncontrollable friction between the testing fixture and the PDMS specimen during the experiments [12]. 


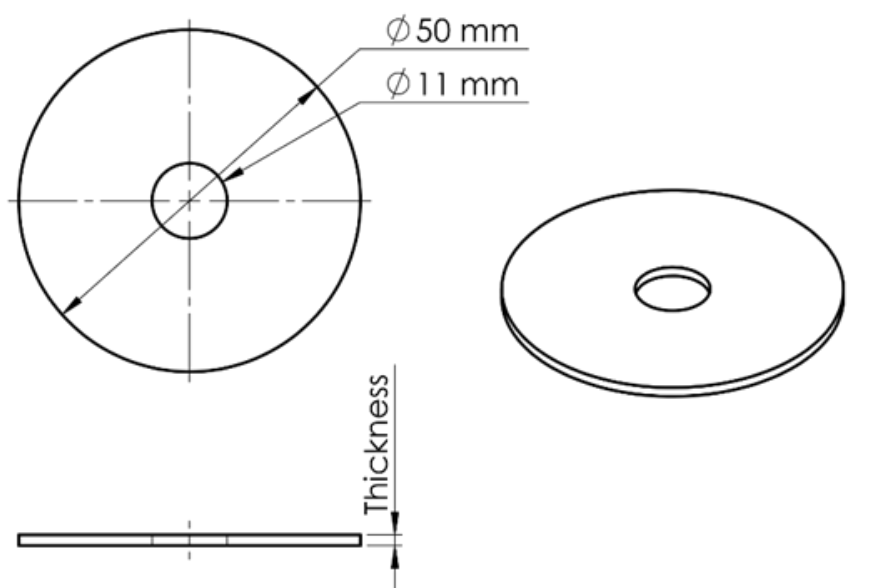

(a)

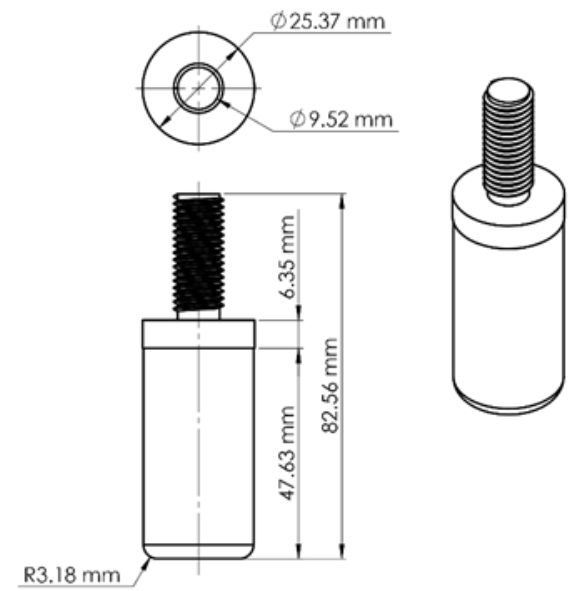

(b)

Fig. 4. Dimension of (a) punch-shear specimens; (b) a punch.

Table 7. Thickness of punch-shear specimens.

\begin{tabular}{cc}
\hline Specimen number & Thickness $(\mathrm{mm})$ \\
\hline 1 & 1.84 \\
2 & 1.50 \\
3 & 1.44 \\
4 & 1.45 \\
\hline
\end{tabular}

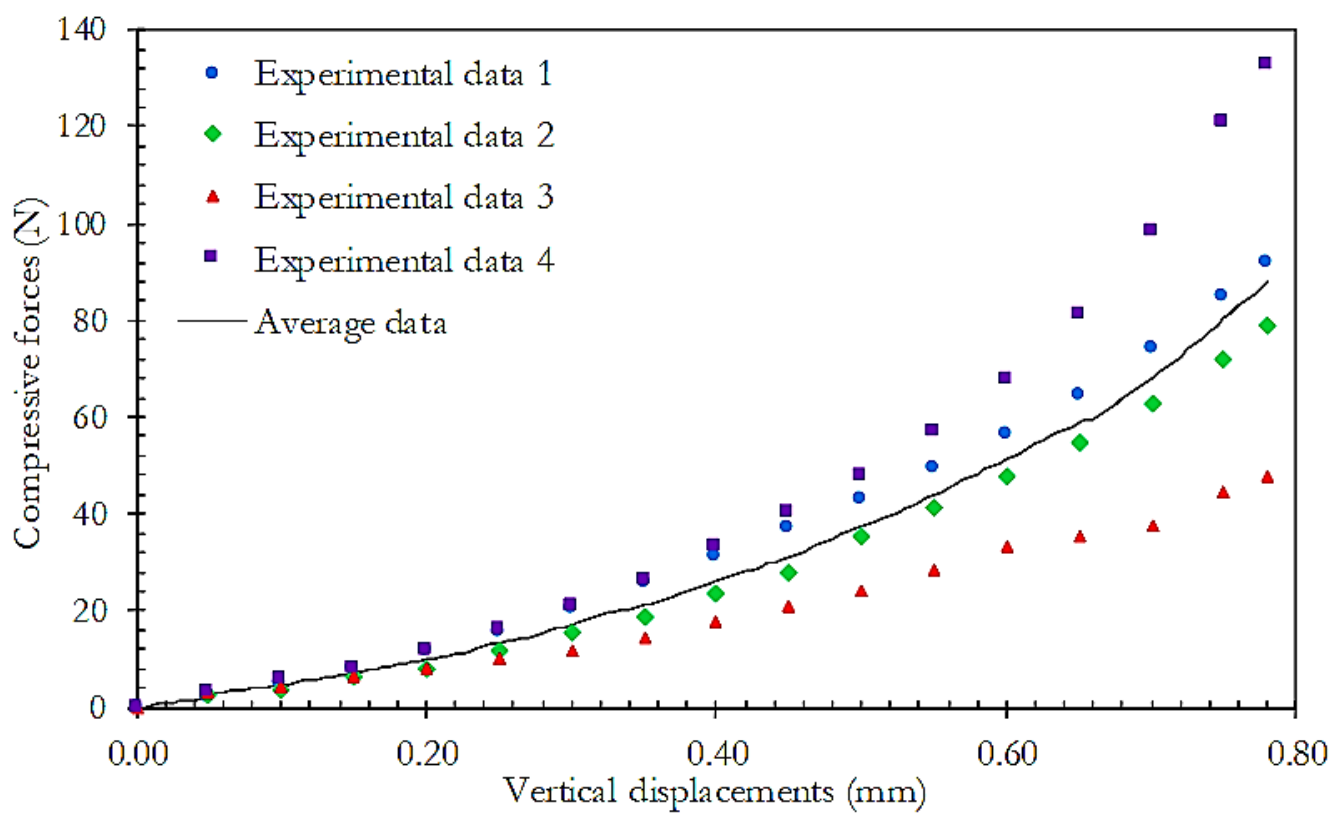

Fig. 5. Plot of compressive forces vs vertical displacements of experimental data and the average data on punch-shear test.

\subsubsection{Finite element analysis of a punch-shear test}

The finite element analyses were performed to determine accuracies of hyperelastic material models for studying structural behaviors under shear loading. Figure 6a shows an assembly drawing of the punch-shear test's fixture. The simplified FE models consisted of a disc-shaped specimen which had an outer diameter 
of $50 \mathrm{~mm}$, an inner diameter of $11 \mathrm{~mm}$ and a thickness of $1.56 \mathrm{~mm}$. The FE models were meshed using the SOLID186 element which was a higher order 3-D 20-node solid element. This model was consisted of 19776 nodes with 3648 elements. The hyperelastic material models consisted of the Mooney-Rivlin 5 parameters, Ogden 3 terms, Yeoh $3^{\text {rd }}$ order and Arruda-Boyce material models where their material constants were illustrated in Table 3-6. The FE model of the punch-shear specimen was divided into 2 volumes along the inner hole of the lower stationary box as shown in Fig. 6b. The volume $A$ was fixed in all DOF while all nodes on the volume $B$ were coupled displacements in the $z$-direction except those nodes on the outer diameter of the volume $B$. Moreover, the contact areas between volumes $A$ and $B$ were set as an initially bonded contact and all nodes on the contact area of the volume $B$ was fixed in the radial direction. The pressure of $0.7 \mathrm{MPa}$ was gradually applied on top of the volume $B$.

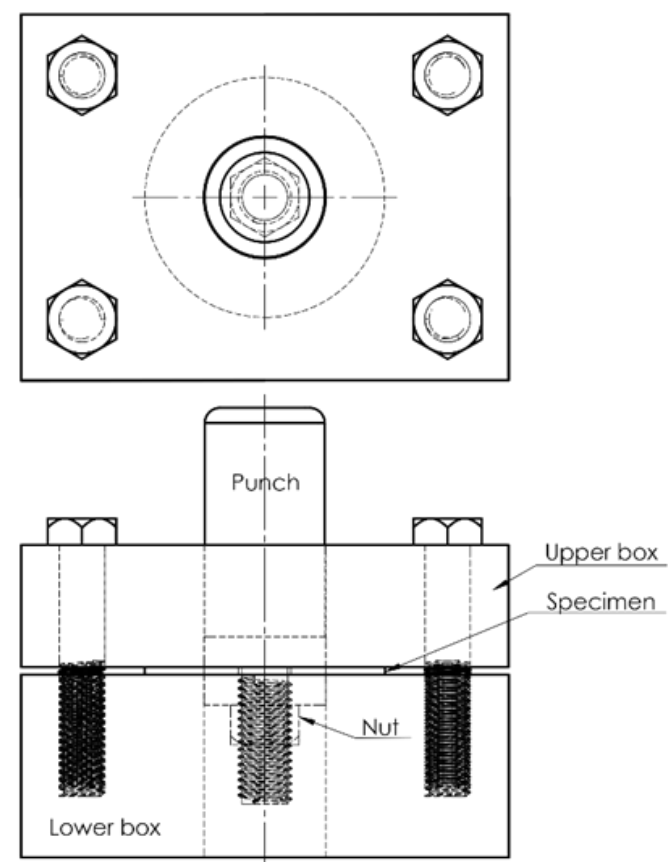

(a)

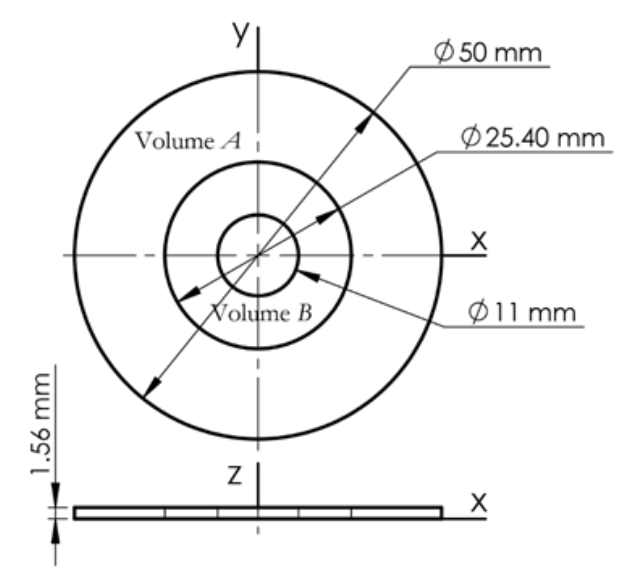

(b)

Fig. 6. (a) Assembly drawing of a Punch-shear fixture; (b) Simplified FE model.

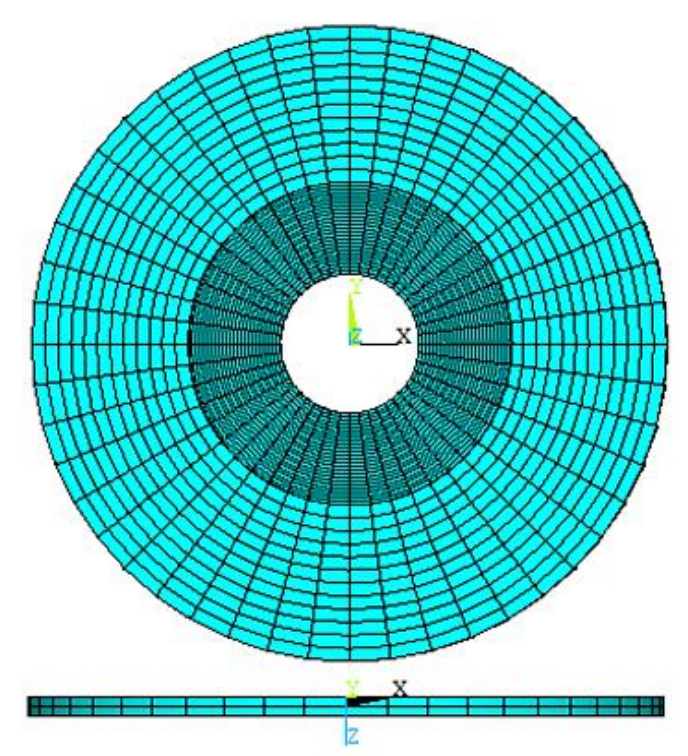

Fig. 7. Finite element model for the punch-shear test. 


\subsection{Finite Element Analyses of a Micropillar}

The anti-fouling surface was fabricated from a PDMS material by Thai Microelectronics Center (TMEC) as shown in Fig. 8. However, this anti-fouling surface was not a robust structure and was easily to deform under small compressive or shear loads. Figure $8 \mathrm{~b}$ illustrates the self-mating of micropillars resulting from shear loading. This research aimed to improve the lateral strength of micropillars to withstand higher shear loads by fabricating an anti-fouling surface which made of PUA core coated with PDMS micropillar [6]. The PDMS material models used in this study was the Yeoh $3^{\text {rd }}$ order material model.

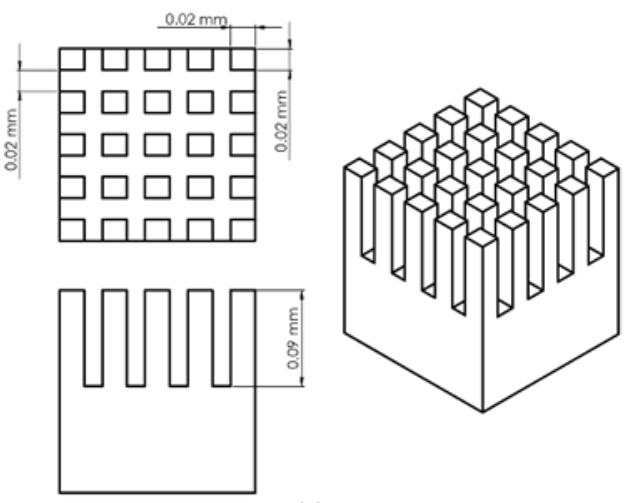

(a)

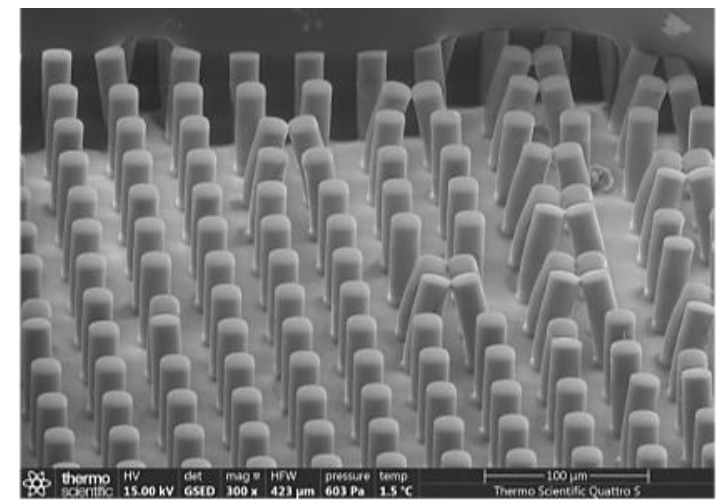

(b)

Fig. 8. (a) Dimension of an anti-fouling surface; (b) Self-mating of micropillars under shear loading.

\subsubsection{Pure PDMS micropillar}

The FE model of a micropillar had dimension of $20 \mu \mathrm{m} \times 20 \mu \mathrm{m} \times 90 \mu \mathrm{m}$ and was meshed by the SOLID185 (8 nodes) element as shown in Fig. 9. This model was consisted of 40131 nodes with 36000 elements. The displacement of $20 \mu \mathrm{m}$ along the $x$-direction was gradually applied on all nodes attached to top of the micropillar while all nodes attached to bottom of the micropillar were fixed in all DOF.

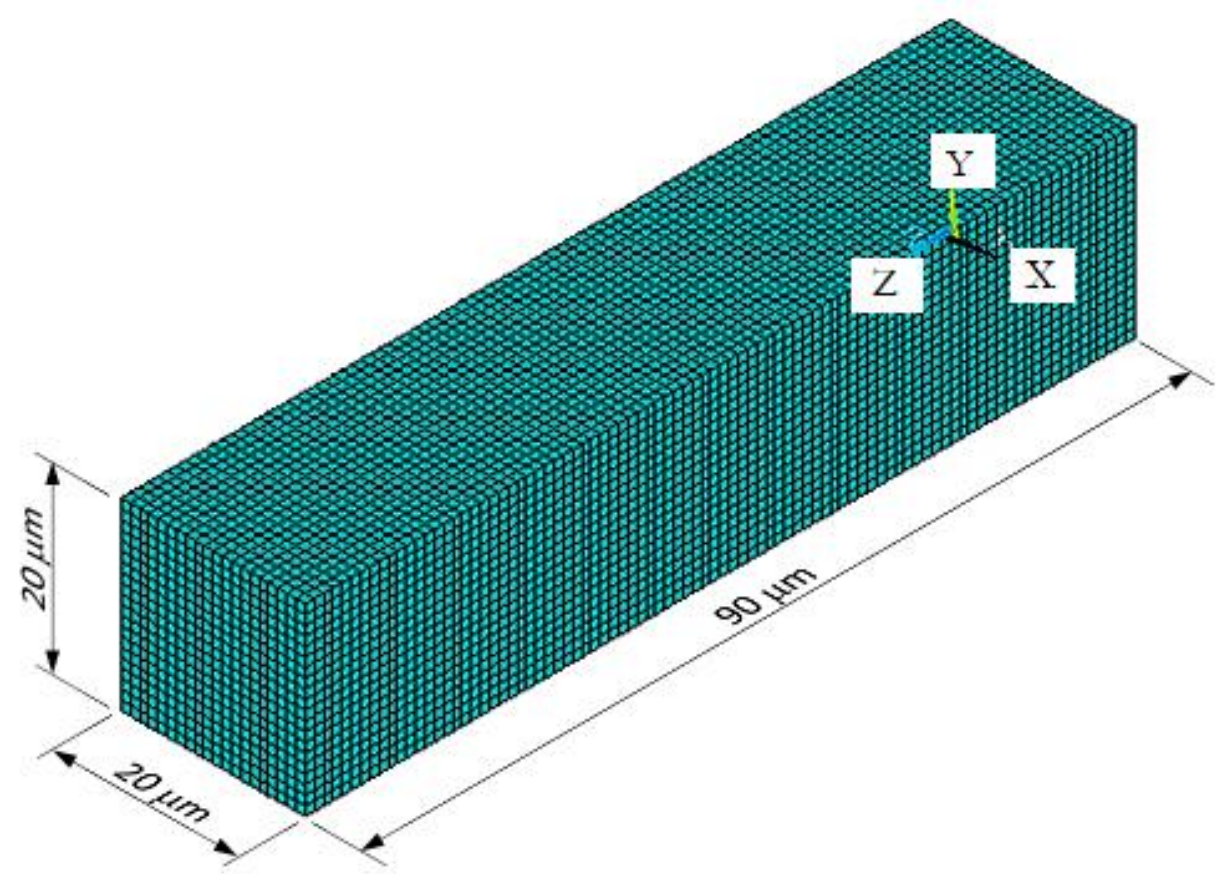

Fig. 9. FE model of a micropillar. 


\subsubsection{PUA Core coated PDMS micropillar}

The micropillar composed of a core made of PUA having dimension of $20 \mu \mathrm{m} \times 20 \mu \mathrm{m} \times 90 \mu \mathrm{m}$ and was coated with the PDMS material for thickness $t$ of $100 \mathrm{~nm}, 125 \mathrm{~nm}, 150 \mathrm{~nm}, 175 \mathrm{~nm}$ and $200 \mathrm{~nm}$ respectively as shown in Fig. 10. The FE model was meshed by the SOLID185 (8-node) element. This model was consisted of 48668 nodes with 44044 elements. Furthermore, the displacement in the $x$ direction of $20 \mu \mathrm{m}$ was gradually applied at all nodes attached to top of the micropillar while all nodes attached to bottom of the micropillar were fixed in all DOF. The material properties of PUA were Young's modulus of $19.8 \mathrm{MPa}$ and Poison's ratio of 0.4 [7].

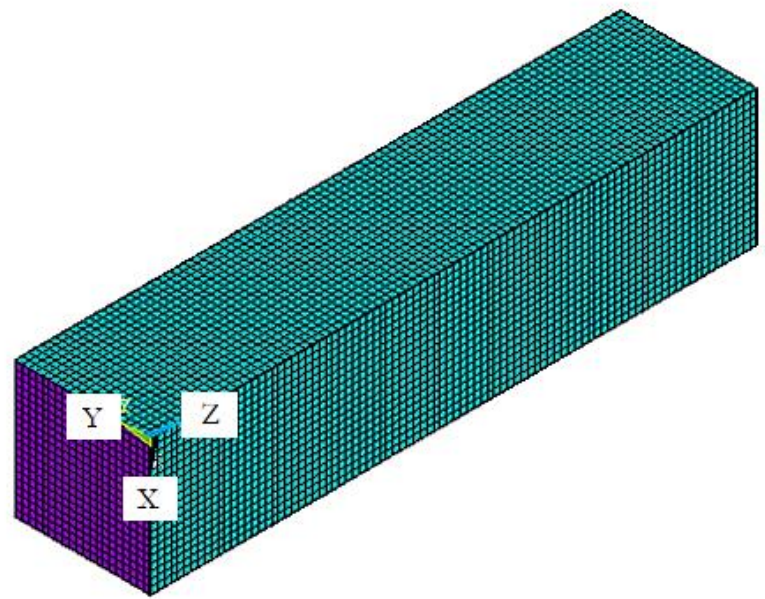

(a)

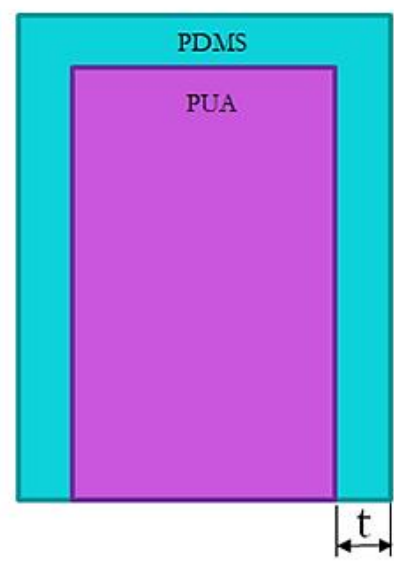

(b)

Fig. 10. (a) The FE model of a PUA core coated PDMS micropillar; (b) a section view.

\section{Results and Discussion}

\subsection{Finite Element Results of a Uniaxial Tensile Test}

The plot of far field true stresses versus true strains for various hyperelastic models were shown in Fig. 11. The accuracies of FE material models were evaluated from Pseudo R-squared which was illustrated in Table 8. The Ogden 3 terms, Arruda-Boyce, Mooney-Rivlin 5 parameters and Yeoh $3^{\text {rd }}$ order material models obtained the accurate FE results which had Pseudo R-squared of 0.99998, 0.99991, 0.99986 and 0.99909 respectively. Figure 12 and 13 showed the contour plot of the stresses and strains in $\approx$ direction of the FE model using the Ogden 3 terms material model and the pulling displacement of $30 \mathrm{~mm}$ respectively. Furthermore, the maximum stress in the $z$-direction was $8.592 \mathrm{MPa}$ found near the fixed location.

Table 8. Pseudo R-squared of the curve fitting of ten models under uniaxial tensile loading condition.

\begin{tabular}{cc}
\hline Hyperelastic material models & Pseudo R-squared \\
\hline Neo-Hookean & 0.73842 \\
Mooney-Rivlin 3 parameters & 0.99580 \\
Mooney-Rivlin 5 parameters & 0.99986 \\
Ogden 1 term & 0.99591 \\
Ogden 2 terms & 0.99906 \\
Ogden 3 terms & 0.99998 \\
Yeoh 1st order & 0.64881 \\
Yeoh 2nd order & 0.98772 \\
Yeoh 3rd order & 0.99909 \\
Arruda-Boyce & 0.99991 \\
\hline
\end{tabular}




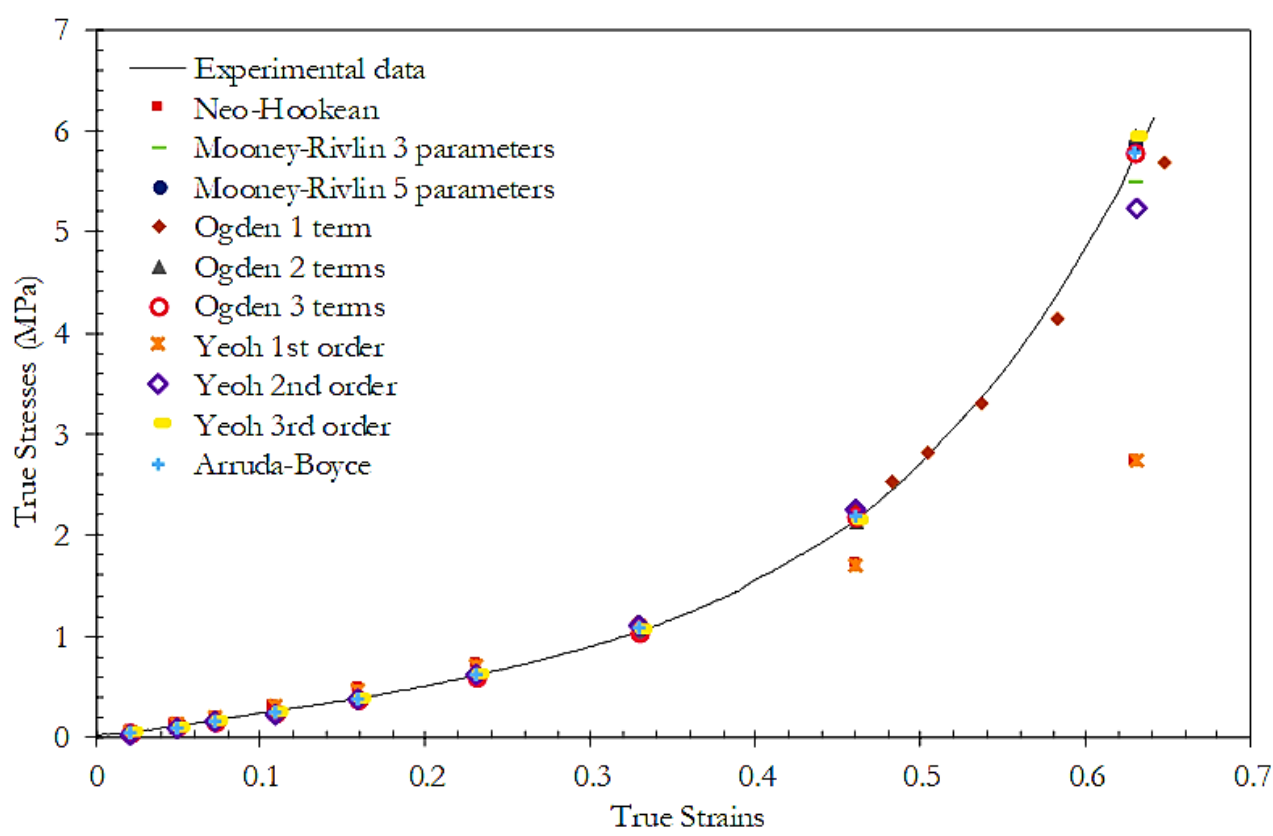

Fig. 11. Plot of true stresses vs true strains of each material models compared to experimental data.

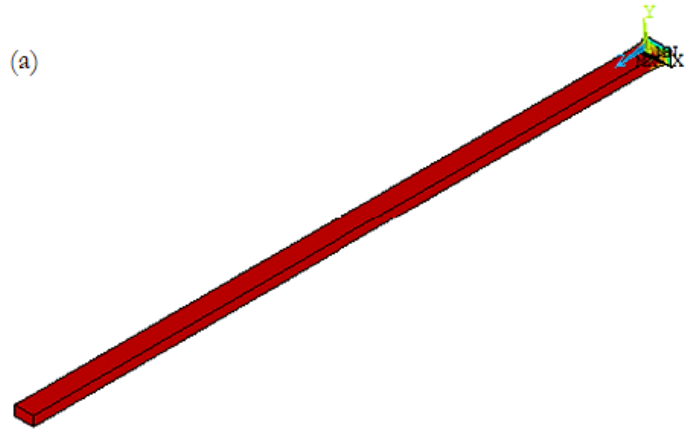

(b)
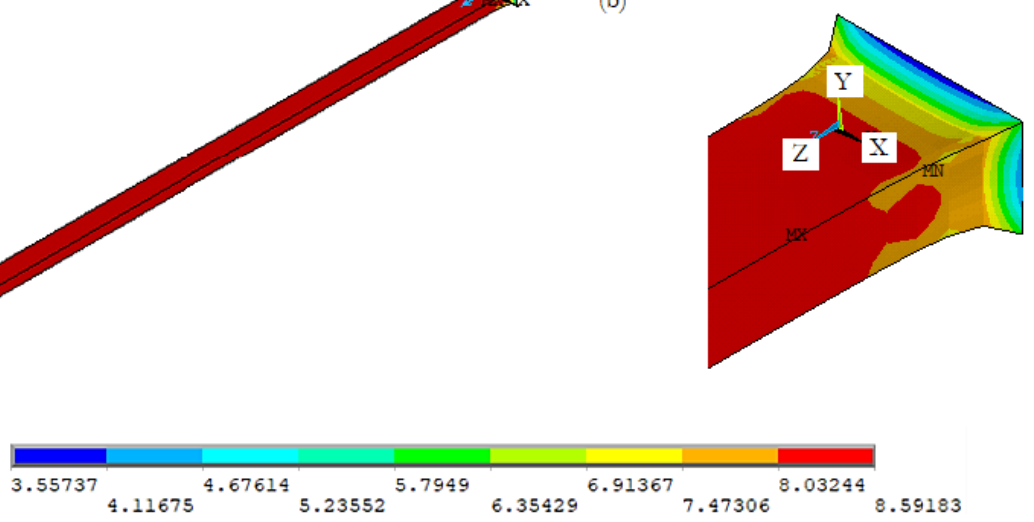

Fig. 12. Contour plot of (a) stresses in the z-direction; (b) stresses in the $z$-direction at the fixed location.

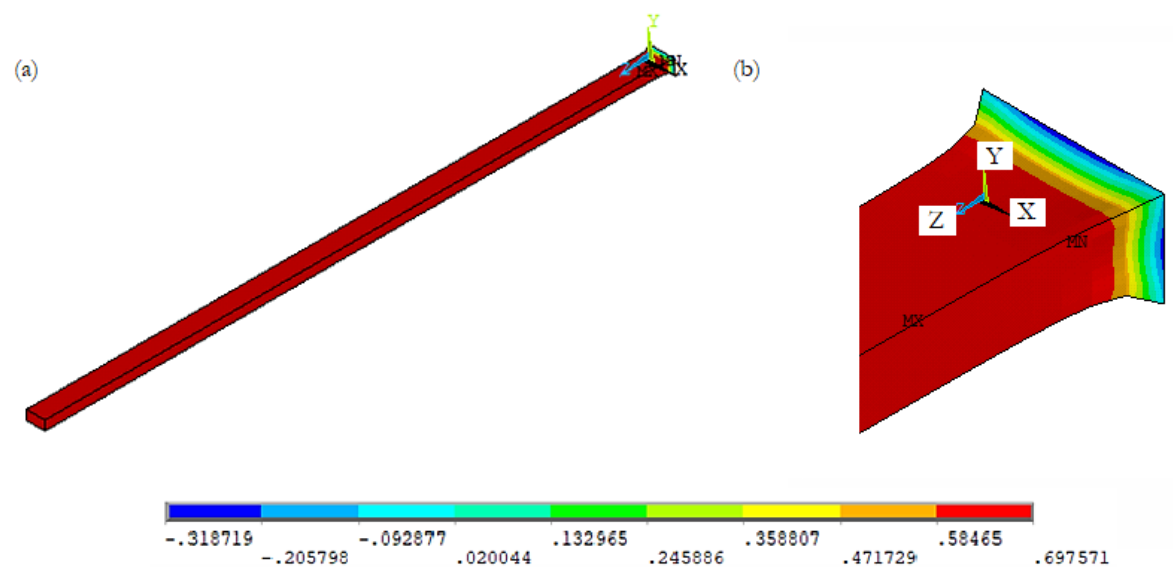

Fig. 13. Contour plot of (a) strains in the $z$-direction; (b) strains in the $z$-direction at the fixed location. 


\subsection{Finite Element Results of a Punch-Shear Test}

The plot of compressive forces versus vertical displacements for various hyperelastic models was shown in Fig. 14. The accuracies of hyperelastic material models were evaluated by Pseudo R-squared which were illustrated in Table 9. Moreover, a warning message of material instabilities appeared on the Mooney-Rivlin 5 parameters FE model which could lead to have an unusual result. Nonetheless, the Yeoh $3^{\text {rd }}$ order models obtained the most correlate and accurate FE results under the low strain region $\left(\varepsilon_{z} \leq 0.19\right)$ which had Pseudo R-squared of 0.98141 as shown in Fig. 15. Figure 16 shows contour plots of FE results using the Yeoh $3^{\text {rd }}$ order material model at applied pressure of $0.24 \mathrm{MPa}$.

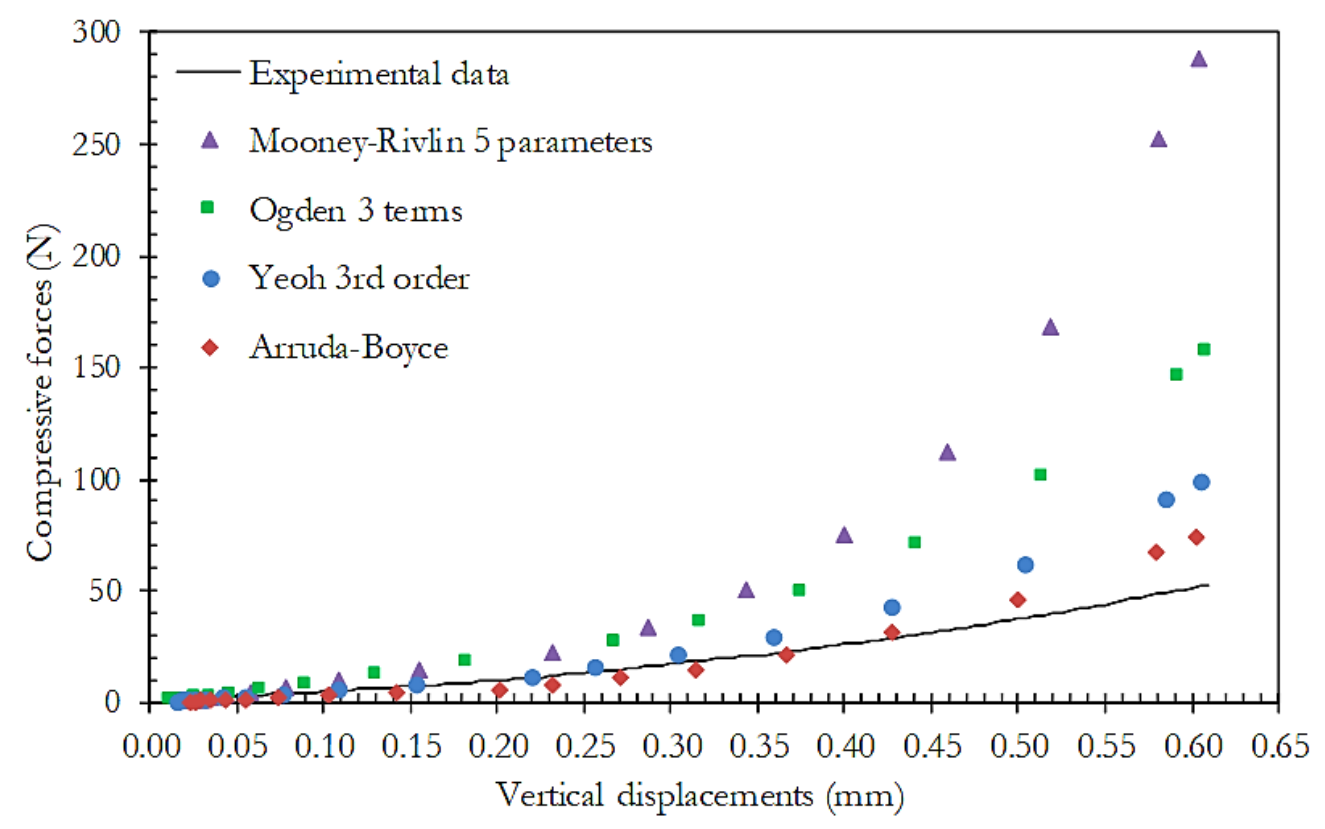

Fig. 14. Plot of compressive forces vs vertical displacements comparing FE results to experimental data from the punch-shear test.

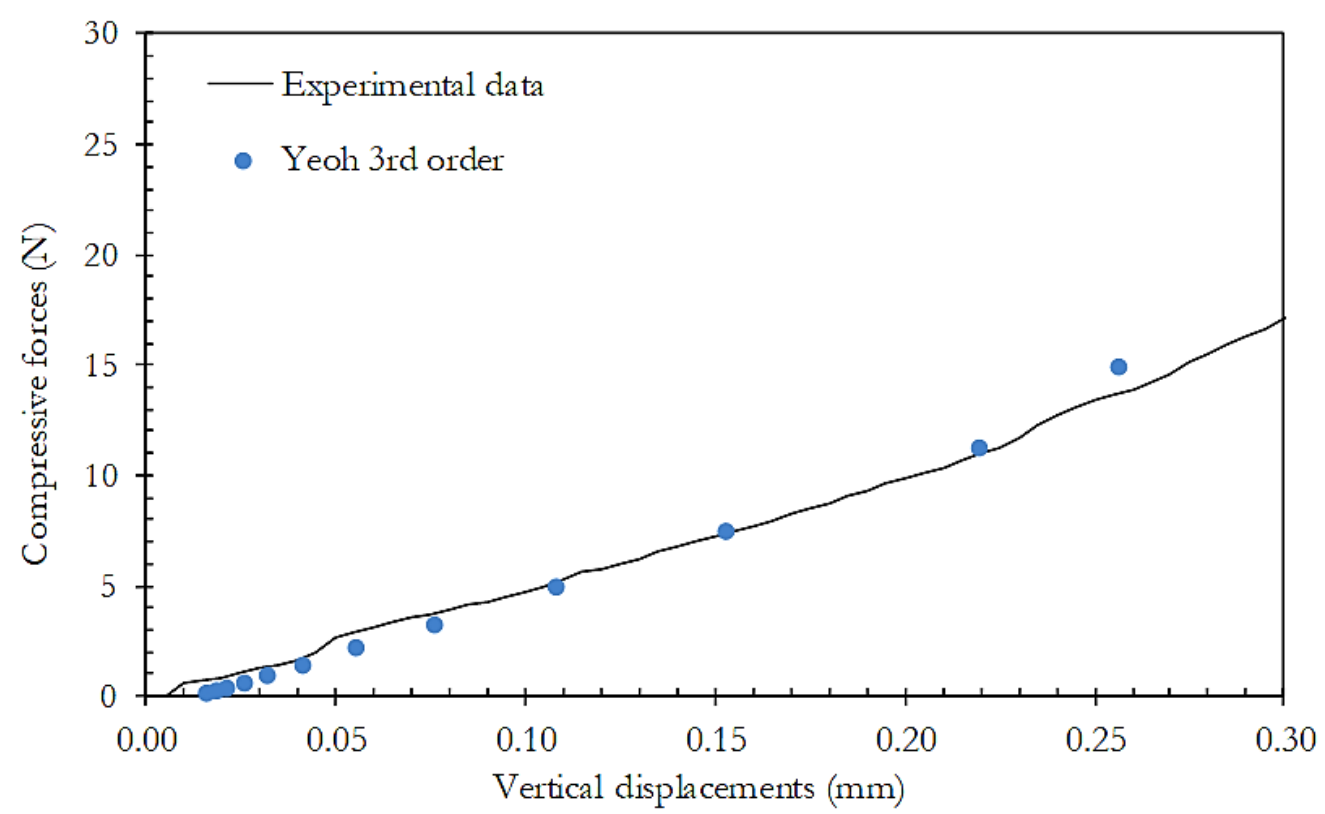

Fig. 15. Plot of compressive forces vs vertical displacements comparing the FE result of the Yeoh $3^{\text {rd }}$ order material model to experimental data from punch-shear test. 
(a)

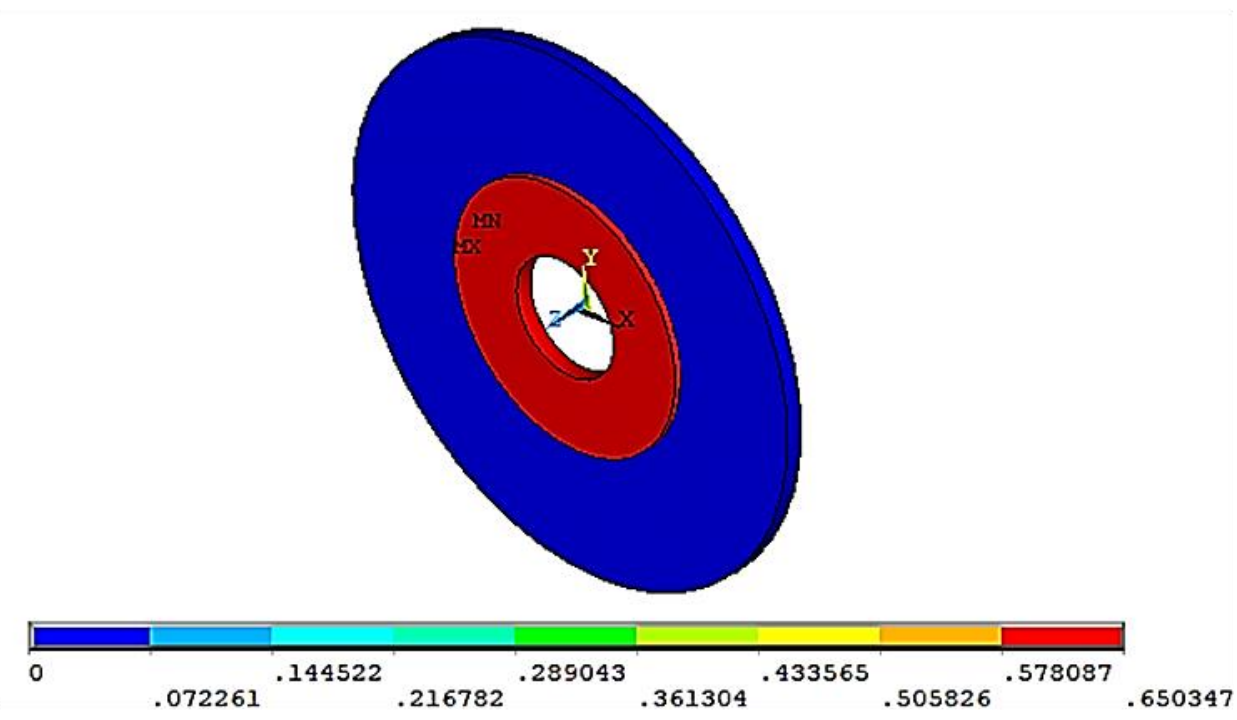

(b)

(c)

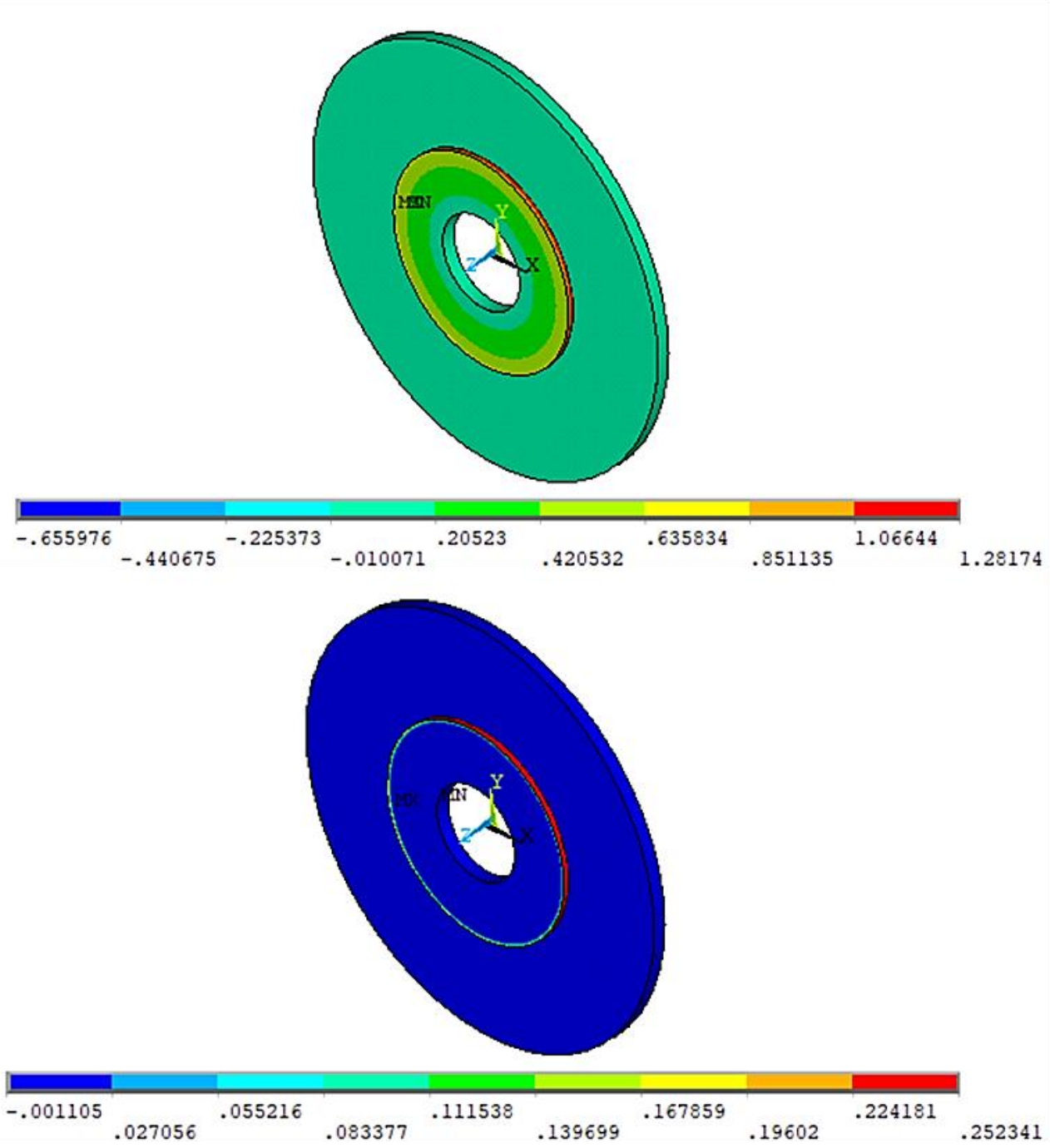

Fig. 16. Contour plot of the FE model using the Yeoh $3^{\text {rd }}$ order material model at applied pressure of 0.24 MPa for (a) deformation in the z-direction (unit in $\mathrm{mm}$ ); (b) stresses in the $z$-direction (unit in MPa); (c) strains in the $z$-direction. 
Table 9. Pseudo R-squared of the curve fitting of four models under punch-shear loading condition.

\begin{tabular}{cc}
\hline Hyperelastic material models & Pseudo R-squared \\
\hline Mooney-Rivlin 5 parameters & -0.88354 \\
Ogden 3 terms & -0.30512 \\
Yeoh 3rd order & 0.98141 \\
Arruda-Boyce & 0.65322 \\
\hline
\end{tabular}

\subsection{The Strength Comparison of Micropillars under Shear Loading}

Table 10 illustrates shear forces required to displace top ends of micropillars to distance of $20 \mu \mathrm{m}$ in the $x$ direction. We found that the shear force on the PUA core coated PDMS material was slightly decreased as the thickness of coated material increases. This might be resulted from the relative soft coat compared to the core material. Moreover, the pure PDMS micropillar needed $3.041 \mu \mathrm{N}$ while the PUA core coated with 100-nm PDMS micropillar needed $26.369 \mu \mathrm{N}$. This was about 8.67 times of the one of the pure PDMS micropillar. Figure 17 shows contour plots of the stresses in z-direction of the pure PDMS micropillar and the PUA core coated with $100 \mathrm{~nm}$-thick PDMS. Figure 18 shows contour plots of the strains in $z$-direction of the pure PDMS micropillar and the PUA core coated with $100 \mathrm{~nm}$-thick PDMS. The maximum stress and strain were found on the fixed end.

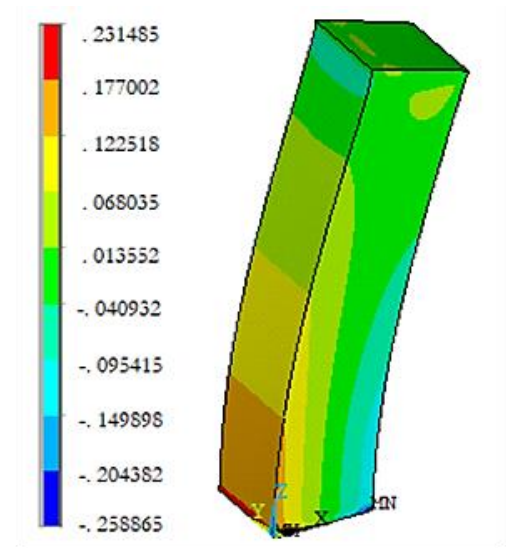

(a)

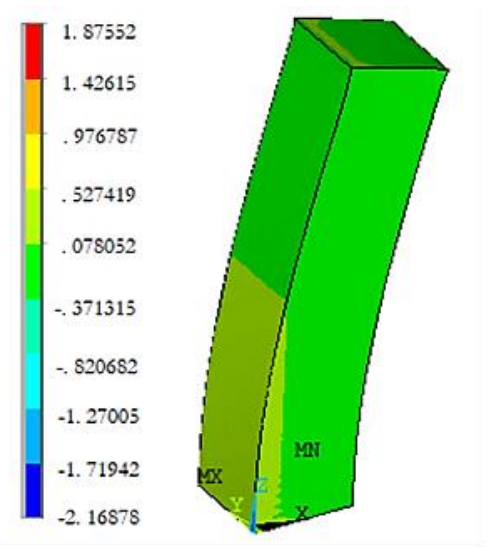

(b)

Fig. 17. Contour plot of stresses in $\approx$-direction (unit in MPa) of (a) pure PDMS; (b) PUA core coated with $100 \mathrm{~nm}$ - thick PDMS.

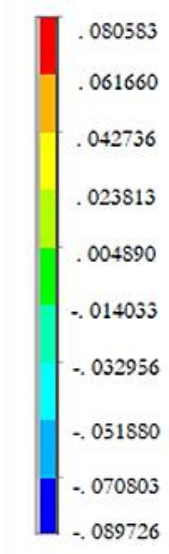

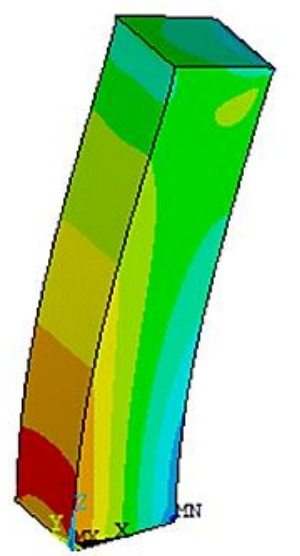

(a)

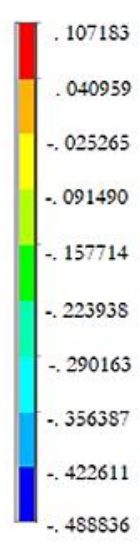

488836

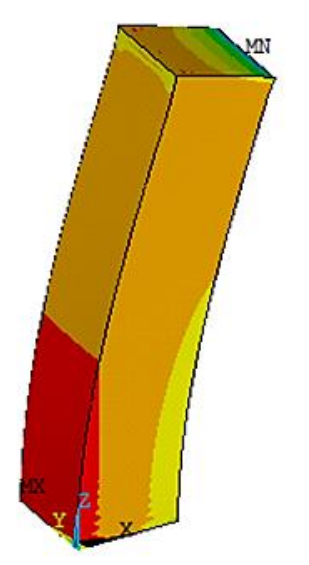

(b)

Fig. 18. Contour plot of strains in the $z$-direction of (a) pure PDMS; (b) PUA core coated with $100 \mathrm{~nm}$ thick PDMS. 
Table 10. Shear force required to displace the top end to a distance of $20 \mu \mathrm{m}$ in $\mathrm{x}$-direction on micropillar.

\begin{tabular}{lcccccc}
\hline & Pure PDMS & \multicolumn{4}{c}{ PUA core coated with PDMS } \\
\hline & & \multicolumn{4}{c}{ Thickness of PDMS (nm) } \\
\cline { 2 - 6 } Shear force $(\mu \mathbf{N})$ & 3.041 & 100 & 125 & 150 & 175 & 200 \\
\cline { 2 - 6 } & & 26.369 & 26.261 & 26.161 & 26.068 & 25.982 \\
\hline
\end{tabular}

\section{Conclusions}

The PDMS material models could derive from experimental data of uniaxial tensile test and could be used to simulate PDMS structures subjected to uniaxial-tensile and punch-shear loading. The most accurate PDMS material model for investigating both uniaxial-tensile and punch-shear loading was the Yeoh $3^{\text {rd }}$ order material model with Pseudo R-squared of 0.99909 (for uniaxial-tensile loading) and 0.98141 (for punch-shear loading). However, if the Yeoh $3^{\text {rd }}$ order material model was used to simulate punch-shear loading, FE results would be valid only for low strain range $\left(\varepsilon_{z} \leq 0.19\right)$. The PUA core coated with 100 nm-thick PDMS micropillar illustrated better lateral strength than one of the pure PDMS micropillar since it could be capable of withstanding up to 8.67-time of the shear force found on the pure PDMS micropillar. Moreover, the thickness of coated PDMS had not showed a significant effect on lateral strength of the composite micropillar. Finally, the $100 \mathrm{~nm}$-coated PDMS micropillar showed both the best lateral strength and cost reduction for production.

\section{Acknowledgment}

The authors gratefully acknowledge Dr. Nithi Atthi, researcher at Thai Microelectronics Center (TMEC), for valuable support and provision of PDMS experimental data.

\section{References}

[1] D. Gomes, N. Souza. and J. Silva, "Using a monocular optical microscope to assemble a wetting contact angle analyser," Measurement, vol. 46, pp. 3623-3627, Jul. 2013.

[2] D. Armani, C. Lui, and N. Aluru, "Re-configurable fluid circuits by PDMS elastomer micromachining," in Twelfth IEEE International Conference on Micro Electro Mechanical Systems, 1999, pp. 222-227.

[3] G. D. Bixler and B. Bhushan, "Biofouling: lessons from nature," Philos T R Soc A., vol. 370, pp. 2381 2417, May 2012.

[4] Z. Wang, A. Volinsky, and N. Gallant, "Crosslinking effect on polydimethylsiloxane elastic modulus measured by custom-built compression instrument," Journal of Applied Polymer Science, vol. 131, no. 9, May 2014.

[5] A. Mata, A. J. Fleischman, and S. Roy, "Characterization of polydimethylsiloxane (PDMS) properties for biomedical micro/nanosystems," Biomedical Microdevices, vol. 7, no. 7, pp. 281-293, Dec. 2005.

[6] W. Bae, M. K. Kwak, H. E. Jeong, C. Pang, H. Jeong, and K. Suh, "Fabrication and analysis of enforced dry adhesives with core-shell micropillars," Soft Matter., vol. 9, no.20, pp. 1422-1427, Nov. 2012.

[7] Y. Rahmawan, S. M. Kang, S. Y. Lee, K. Suh, and S. Yang, "Enhanced shear adhesion by mechanical interlocking of dual-scaled elastomeric micropillars with embedded silica particles," Macromolecular Reaction Engineering, vol. 7, no. 10, pp. 616-623, 2013.

[8] F. Xie, H. Zhou, W. Zhao, and L. Huang, "A comparative study on the mechanical behavior of intervertebral disc using hyperelastic finite element model," Technology and Health Care, vol. 25, pp. 177$187,2017$.

[9] R. Tobajas, E. Ibarz, and L. Gracia, "A comparative study of hyperelastic constitutive models to characterize the behavior of a polymer used in automotive engines," in Proc 2nd International Electronic Conference on Materials, April 2016, pp. 2-16.

[10] J. Smardzewski, I. Grbac, and S. Prekrat, "Nonlinear mechanics of hyper elastic polyurethane furniture foams," Druna industrija, vol. 59, no. 13, pp. 23-28, Jun. 2008. 
[11] A. Nomoto, H. Yasutaka, S. Oketani, and A. Matsuda, "2-dimensional homogenization FEM analysis of hyperelastic foamed rubber," Procedia Engineering, vol. 147, no. 14, pp. 431-436, Jan. 2016.

[12] D. Huri and T. Mankovits, "Comparison of the material models in rubber finite element analysis," IOP Conference Series: Materials Science and Engineering, vol. 393, no. 15, 2018.

[13] J. Phromjan and C. Suvanjumrat, "A suitable constitutive model for solid tire analysis under quasistatic loads using finite element method," Engineering Journal, vol. 22, no. 2, pp. 141-155, Mar. 2018.

[14] B. J. Munroe and J. A. Sherwood, "Finite element modeling of a baseball," Procedia Engineering, vol. 34, no. 16, pp. 610-615, Jan. 2012.

[15] M. Gajewski, R. Szczerba, and S. Jemiolo, "Modelling of elastomeric bearings with application of Yeoh Hyperelastic Material Model," Procedia Engineering, vol. 111, no. 17, pp.220-227, Jan. 2015.

[16] M. L. Rathod, N. Pareek, S. Agrawal, S. Jaddivada, D. W. Lee, and N. Gundiah, "Engineered ridge and micropillar array detectors to quantify the directional migration of fibroblasts," RSC Advances, vol. 7, no. 18, pp. 51436-51443, Oct. 2017.

[17] V. Carlescu, G. Prisacaru, and D. N. Olaru, "FEM simulation on uniaxial tension of hyperelastic elastomers," Applied Mechanics and Materials, vol. 659, no. 1, pp. 57-62, May 2014.

[18] T. K. Kim, J. K. Kim, and O. C. Jeong, "Measurement of nonlinear mechanical properties of PDMS elastomer," Microelectronic Engineering, vol. 88, no. 4, pp. 1982-1985, Aug. 2011.

[19] L. C. S. Nunes, "Mechanical characterization of hyperelastic polydimethylsiloxane by simple shear test," Materials Science and Engineering, vol. 528, no.19, pp. 1799-1804, Jan. 2011.

[20] A. Ali, M. Hosseini, and B. B. Sahari, "A review of constitutive models for rubber-like materials," American Journal of Engineering and Applied Sciences., vol. 3, no. 610, pp. 232-239, 2010. 